\title{
Prevention of Scaling of Mild Steel
}

$\mathrm{I}^{\mathrm{N}}$ the heat treatment of steel during manufacture, scale is formed on the surface by oxidation. This involves a loss of metal which in the aggregate is enormous. Moreover, the actual monetary loss is much increased from the damage to the surface, necessitating machining, and from the production of wasters outside specified dimensions.

The factors affecting scaling are temperature, period of heating, nature of the steel and furnace atmosphere; but of these, all but the furnace atmosphere are determined by considerations quite apart from those of minimum scale formation. The normal method of minimising scaling is to heat in a reducing atmosphere, which in the case of a coal-fired furnace means the emission of smoke and, at the same time, a fuel loss represented by the potential heat in the incompletely burned products of combustion. In the past, so well established was the tradition that a smoky atmosphere was essential to reheating furnaces, that steel-makers were exempt from many of the provisions of the Smoke Abatement Acts.

The influence of the composition of the atmosphere has received a systematic survey at the University of Leeds, and is described in a report by Dr. H. C. Millett and Prof. J. W. Cobb presented to the Institution of Gas Engineers in November last. Special attention was given to the influence of sulphur dioxide, oxygen or reducing gases in the furnace atmosphere. 'The 'neutral' furnace atmosphere, representing the products of the complete combustion of a fuel with no excess of air, was itself oxidising, water vapour being a more powerful oxidant than carbon dioxide. The addition of small and increasing percentages of oxygen to the 'neutral' atmosphere was accompanied by a rapid increase in the scaling, whereas similar small quantities of reducing gases were much less effective in restraining scaling.

Observations made upon the influence of the sulphur content of the fuel disclosed some interesting features. It was found, for example, that at $1,000^{\circ} \mathrm{C}$., $0 \cdot 10$ per cent sulphur dioxide in the 'neutral' atmo. sphere, the quantity forthcoming from an average coal or fuel oil, gave the same increase in scaling as $1 \cdot 0$ per cent oxygen in the furnace atmosphere. These results bear on the question of the degree of purification necessary when coke oven gas is to be used for steel manufacture.

The authors conclude that the best results as regards freedom from scaling will only be obtained from furnaces so designed, constructed and controlled in use that an atmosphere containing no free oxygen and a minimum of sulphur dioxide and steam can be consistently maintained, but that complete elimination of scaling, as is sometimes required, can only be brought about efficiently by indirect heating, in which the bulk of the products of combustion does not come into contact with the metal.

\section{Petroleum Research}

$\mathrm{T}$ HE petroleum industry in America has been initiated and developed practically within the last thirty years; yet it is to-day there regarded as one of the most important industries. Not only is about eighty per cent of the rated horse-power of that country generated by oil and its products, but in addition the petroleum industry is one of the largest purchasers of steel, iron and motor-vehicles, etc. At the same time it is the second largest customer of shipyards, which supply the necessary tank ships for transport.

The Gulf Research and Development Corporation, Harmaville, Pa., has recently circulated a brochure which delineates the part played by industrial research in the solution of scientific, economic and social problems arising in the past in connexion with exploitation of petroleum, and indicates lines on which immediate problems are to be tackled. This is of particular interest in that it becomes evident during perusal that there is no phase of petroleum discovery, exploitation, refining or marketing which is not governed by laboratory or field data obtained as the result of intensive research. In exploration work, the geophysicist has superseded the less reliable, casual prospector, and by magnetic, gravitational, seismic or other methods is able to obtain a more or less accurate map of rocks lying many thousands of feet below the surface. In production, small samples of rock can be removed from the boring and analyses made to determine porosity, permeability and other relevant characteristics. Further, by correlation of results an estimate can be made of total thickness and areal extent of oil-bearing strata.

The annual losses of the petroleum industry from mechanical failure of equipment and corrosion amount to some millions of dollars. This alarming fact shows how vital it is that research should be prosecuted to find materials most suited to withstand the particular strain imposed upon them by petroleum engineering. Already it has been proved that steel of low carbon content and containing up to $4 \cdot 5$ per cent of nickel is better than the ordinary type for this work; this is only one of many important discoveries which help to reduce losses to the industry as a whole.

The aim of research workers is to reach a point where specifications can be issued to the industry for all classes of materials, which will guaranteo maximum return in service for each dollar invested in equipment.

Enormous scope is offered to research workers in selection of the best product for a particular purpose. Already there are more than four hundred uses to which petroleum products are put, for each of which it is necessary to provide many different material because of variations in application. When it is considered that technical progress is being mado every day in each of the industries served by petroleum, then it must be admitted that the field of petroleum products research itself is correspond. ingly boundless. 